\title{
Developmental Switch in Synaptic Mechanisms of Hippocampal Metabotropic Glutamate Receptor-Dependent Long-Term Depression
}

\author{
Elena D. Nosyreva and Kimberly M. Huber \\ Center for Basic Neuroscience, Department of Physiology, University of Texas Southwestern Medical Center, Dallas, Texas 75390-9111
}

\begin{abstract}
The presynaptic and postsynaptic properties of synapses change over the course of postnatal development. Therefore, synaptic plasticity mechanisms would be expected to adapt to these changes to facilitate alterations of synaptic strength throughout ontogeny. Here, we identified developmental changes in long-term depression (LTD) mediated by group 1 metabotropic glutamate receptors (mGluRs) and dendritic protein synthesis in hippocampal CA1 slices (mGluR-LTD). In slices prepared from adolescent rats [postnatal day 21 (P21) to P35], mGluR activation induces LTD and a long-term decrease in AMPA receptor (AMPAR) surface expression, both of which require protein synthesis. In neonatal animals (P8-P15), mGluR-LTD is independent of protein synthesis and is not associated with changes in the surface expression of AMPARs. Instead, mGluR-LTD at neonatal synapses results in large decreases in presynaptic function, measured by changes in paired-pulse facilitation and the rate of blockade by the use-dependent NMDA receptor blocker (+)-5-methyl-10,11dihydro-5H-dibenzo[a,d]cyclohepten-5,10-imine maleate. Conversely, mGluR-LTD at mature synapses results in little or no change in presynaptic function, suggesting a postsynaptic mechanism of expression. The developmental switch in the synaptic mechanisms of LTD would differentially affect synapse dynamics and perhaps information processing over the course of postnatal development.
\end{abstract}

Key words: metabotropic glutamate receptor; long-term depression; protein synthesis; AMPA receptor endocytosis; hippocampus; CA1

\section{Introduction}

There is growing evidence that both the presynaptic and postsynaptic properties of synapses change over the course of postnatal development. Nascent synapses are characterized by high presynaptic release probability and few postsynaptic AMPA receptors (AMPARs). Synapse maturation is accompanied by the acquisition of AMPARs and decreases in neurotransmitter release probability (Bolshakov and Siegelbaum, 1995; Pouzat and Hestrin, 1997; Liao et al., 1999; Petralia et al., 1999; Reyes and Sakmann, 1999; Pickard et al., 2000; Wasling et al., 2004) (but see Dumas and Foster, 1995; Hsia et al., 1998). For developing synapses to remain plastic over the course of synapse maturation, plasticity mechanisms must adapt with these changing synaptic properties. Indeed, there is evidence for changes in the mechanisms of longterm potentiation during synapse development (Yasuda et al., 2003). Here, we demonstrate that both the synaptic and molecular mechanisms of synaptic long-term depression (LTD) change over the course of synapse maturation in area CA1 of the rat hippocampus. Specifically, we examined the developmental

\footnotetext{
Received Sept. 3, 2004; revised Jan. 21, 2005; accepted Feb. 4, 2005.

This work was supported by National Institutes of Health Grant R01NS045711, the McKnight Foundation, and the FRAXA Research Foundation. K.M.H. is a Southwestern Medical Foundation Endowed Scholar in Biomedical Research. We thank Christine Daly and Lenora Volk for technical assistance and Ege Kavalali and Jay Gibson for helpfu discussions.

Correspondence should be addressed to Kimberly Huber, Center for Basic Neuroscience, University of Texas Southwestern Medical Center, 5323 Harry Hines Boulevard, Dallas, TX 75390-9111. E-mail: kimberly.huber@utsouthwestern.edu.

DOI:10.1523/JNEUROSCI.3652-04.2005

Copyright $\odot 2005$ Society for Neuroscience $\quad$ 0270-6474/05/252992-10\$15.00/0
}

changes of LTD, which rely on group 1 metabotropic glutamate receptors (mGluRs) and dendritic protein synthesis (mGluRLTD) (Huber et al., 2000). This work was motivated by findings that group $1 \mathrm{mGluR}$ function (measured as phosphoinositide turnover) and synaptic polyribosome number peak during the period of synapse formation and maturation [approximately postnatal day 7 (P7) to P15 in the hippocampus], suggesting that mGluR-LTD plays a significant role in the plasticity of developing synapses (Steward and Falk, 1985, 1991; Nicoletti et al., 1986; Dudek et al., 1989; Palmer et al., 1990; Casabona et al., 1997).

The developmental regulation and site of expression of mGluR-LTD in the hippocampus has been controversial. Some studies suggest that mGluR-LTD is only observed at early developmental time periods in area CA1 (P7-P11) (Bolshakov and Siegelbaum, 1994; Overstreet et al., 1997). However, others indicate that mGluR-LTD is restricted to adult animals (Kemp et al., 2000). There is general agreement that mGluR-LTD is induced postsynaptically (Bolshakov and Siegelbaum, 1994; Oliet et al., 1997; Watabe et al., 2002). However, many studies of mGluRLTD of immature neurons (P4-P11) conclude that mGluR-LTD is expressed presynaptically using both electrophysiological and optical methods (Bolshakov and Siegelbaum, 1994; Oliet et al., 1997; Fitzjohn et al., 2001; Zakharenko et al., 2002; Feinmark et al., 2003; Rammes et al., 2003).

Evidence for a postsynaptic mechanism of mGluR-LTD expression comes from studies demonstrating that the selective group $1 \mathrm{mGluR}$ agonist $R, S$-dihydroxyphenylglycine (DHPG), which induces LTD, results in endocytosis and a persistent de- 
crease in postsynaptic AMPARs and NMDA receptors (NMDARs), which requires protein synthesis (Snyder et al., 2001; Xiao et al., 2001). DHPG-induced LTD is blocked by the postsynaptic injection of endocytosis and protein synthesis inhibitors (Snyder et al., 2001; Xiao et al., 2001), suggesting a postsynaptic mechanism of expression.

Here, we find a developmental switch in the protein synthesis dependence and synaptic locus of mGluR-LTD, which occurs between the second and fourth postnatal week. This switch may occur to accommodate the changing properties of synapses and may have consequences for information processing over the course of postnatal development.

\section{Materials and Methods}

Drugs. D,L-AP-5, (+)-5-methyl-10,11-dihydro-5H-dibenzo[a,d]cyclohepten5,10-imine maleate (MK801) (Tocris Cookson, Ellisville, MO), anisomycin, and picrotoxin (Sigma, St. Louis, MO) were prepared fresh in artificial CSF (ACSF). The cannabinoid 1 receptor $\left(\mathrm{CB}_{1} \mathrm{R}\right)$ antagonist 1-(2,4-dichlorophenyl)-5-(4-iodophenyl)-4-methyl- $N$-4-morpholinyl$1 \mathrm{H}$-pyrazole-3-carboxamide (AM281) and $R$ - $(+)$-[2,3-dihydro-5methyl-3-[(morpholinyl)methyl]pyrrolo[1,2,3-DE]-1,4-benzoxazin-6yl]-(1-naphtmalenyl)methanone mesylate (WIN55,212-2) (Tocris Cookson) were prepared as a $1000 \times$ stocks in DMSO, used fresh or kept as stocks at $-20^{\circ} \mathrm{C}$, and diluted to final concentration in ACSF. Slices were preincubated in antagonists or inhibitors for 20-30 min before DHPG or paired-pulse low-frequency stimulation (PP-LFS). The effects of all of the pharmacological treatments on LTD were evaluated by comparing interleaved control and treated slices.

Electrophysiology. Long-Evans hooded rats were obtained from Charles River Laboratories (Wilmington, MA). Hippocampal slices (400 $\mu \mathrm{m}$ ) were prepared from 8- to 35-d-old rats. Rats were anesthetized with the barbiturate pentobarbital $(50 \mathrm{mg} / \mathrm{kg})$ and decapitated soon after the disappearance of corneal reflexes. The brain was removed and dissected and then sliced using a vibratome (VT 1000S; Leica, Nussloch, Germany) in ice-cold dissection buffer containing the following (in $\mathrm{mM}$ ): $2.6 \mathrm{KCl}$, $1.25 \mathrm{NaH}_{2} \mathrm{PO}_{4}, 26 \mathrm{NaHCO}_{3}, 0.5 \mathrm{CaCl}_{2}, 5 \mathrm{MgCl}_{2}, 212$ sucrose, and 10 dextrose. Area CA3 was surgically removed from each slice immediately after sectioning. The slices were transferred into a reservoir chamber filled with ACSF containing the following (in mM): $124 \mathrm{NaCl}, 5 \mathrm{KCl}, 1.25$ $\mathrm{NaH}_{2} \mathrm{PO}_{4}, 26 \mathrm{NaHCO}_{3}, 2 \mathrm{CaCl}_{2}, 2 \mathrm{MgCl}_{2}$, and 10 dextrose. Slices were allowed to recover for $2-5 \mathrm{~h}$ at $30^{\circ} \mathrm{C}$. ACSF and dissection buffer were equilibrated with $95 \% \mathrm{O}_{2}$ and $5 \% \mathrm{CO}_{2}$.

For recording, slices were transferred to a submerged recording chamber, maintained at $30^{\circ} \mathrm{C}$, and perfused continuously with ASCF at a rate of $2-3 \mathrm{ml} / \mathrm{min}$. Field potentials (FPs) were recorded with extracellular recording electrodes $(1 \mathrm{M} \Omega$ ) filled with ACSF and placed in stratum radiatum of area CA1. FPs were evoked by monophasic stimulation (duration, $200 \mu \mathrm{s}$ ) of Schaffer collateral/commissural afferents with a concentric bipolar tungsten stimulating electrode (Frederick Haer Company, Bowdoinham, ME). NMDA receptor-mediated FPs were isolated in a modified ASCF containing the following (in $\mathrm{mm}$ ): $3 \mathrm{CaCl}_{2}, 0.1$ $\mathrm{MgCl}_{2}, 2.5 \mathrm{KCl}, 0.02 \mathrm{DNQX}, 0.001$ glycine, and 0.1 picrotoxin. Stable baseline responses were collected every $30 \mathrm{~s}$ using a stimulation intensity $(10-30 \mu \mathrm{A})$, yielding $50-60 \%$ of the maximal response. FPs were filtered at $2 \mathrm{kHz}$, acquired, and digitized at $10 \mathrm{kHz}$ on a personal computer using custom software (LabVIEW; National Instruments, Austin, TX). The initial slope of the FP was used to measure the stability of synaptic responses and quantify the magnitude of LTD. mGluR-LTD was induced by pairs of stimuli (interstimulus interval, $50 \mathrm{~ms}$ ) delivered at $1 \mathrm{~Hz}$ for 15 min (1800 pulses; PP-LFS), by stimulation delivered at $5 \mathrm{~Hz}$ for $3 \mathrm{~min}$ (900 pulses; $5 \mathrm{~Hz}$ ), or by application of $100 \mu \mathrm{M}$ DHPG (Tocris Cookson) for $5 \mathrm{~min}$. For paired-pulse facilitation (PPF) experiments, pairs of presynaptic stimulation (interpulse interval, $50 \mathrm{~ms}$ ) were delivered every $30 \mathrm{~s}$ throughout the experiment.

The group data were analyzed as follows: (1) the initial slopes of the FP were expressed as percentages of the preconditioning or DHPG baseline average; (2) the time scale in each experiment was converted to time from the onset of conditioning or DHPG; and (3) the time-matched, normal- ized data were averaged across experiments and expressed as means \pm SEM. The PPF ratio was obtained by dividing the initial field potential slope from the second pulse (FP2) by that of the first pulse (FP1) and then normalizing to the pre-DHPG baseline PPF value. For example, a $20 \%$ increase in PPF represents a change in the PPF or FP2/FP1 ratio from 1.6 to 1.92 . Time constants $(\tau)$ of the rate of MK801 blockade of NMDAR FPs were determined by fitting the decay of the maximum amplitude of NMDAR FPs in MK801 with a double exponential using Origin analysis software (Microcal Software, Northampton, MA). Significant differences were determined by a Student's independent or paired $t$ test (if indicated). $p<0.05$ was considered to represent significant differences. For correlation analysis, correlation coefficients were determined, and $z$ tests were performed to determine $p$ values using StatView software (SAS Institute, Cary, NC).

Biochemical measurements of surface-expressed AMPA receptors. Biotinylation experiments were performed as described previously (Chung et al., 2000; Heynen et al., 2003). Hippocampal slices were prepared as described for electrophysiology experiments. After a 2-3 h recovery period in ACSF, slices were treated with DHPG (5 min), NMDA (3 min), or ACSF (control). DHPG experiments were performed in the presence of $100 \mu \mathrm{M}$ D,L-AP-5. From each rat, two to three slices were pooled together for one condition. Slices were placed on ice to stop endocytosis and then were washed with ice-cold ACSF and incubated in ACSF containing 1 $\mathrm{mg} / \mathrm{ml}$ sulfo-NHS-LC-biotin (Pierce, Rockford, IL) for $10 \mathrm{~min}$ on ice. To quench the biotin reaction, slices were washed three times with Trisbuffered saline and homogenized in a modified radioimmunoprecipitation assay (RIPA) buffer containing $50 \mathrm{~mm}$ Tris- $\mathrm{HCl}$, pH 7.4, 1\% Triton X-100, 0.1\% SDS, 0.5\% Na-deoxycholate, $150 \mathrm{~mm} \mathrm{NaCl}, 2$ mM EDTA, 50 mм NaH ${ }_{2} \mathrm{PO}_{4}, 50 \mathrm{~mm} \mathrm{NaF}, 10 \mathrm{~mm} \mathrm{Na}_{4} \mathrm{P}_{2} \mathrm{O}_{7}, 1 \mathrm{~mm} \mathrm{Na}_{3} \mathrm{VO}_{4}$, and Protease Inhibitor Cocktail III (Calbiochem, La Jolla, CA). The homogenates were centrifuged at $14,000 \times g$ for $10 \mathrm{~min}$ at $4^{\circ} \mathrm{C}$. Protein concentrations were measured with a BCA Protein Assay (Pierce). Protein $(15 \mu \mathrm{g})$ was removed for total protein measurements. Protein $(150 \mu \mathrm{g})$ was then mixed with $150 \mu$ l of UltraLink immobilized NeutrAvidin beads (Pierce) by rotating for $2 \mathrm{~h}$ at $4^{\circ} \mathrm{C}$. The beads were washed with 10 vol of RIPA buffer and then eluted with SDS-PAGE sample buffer supplemented with 50 $\mathrm{mm}$ dithiothreitol for $20 \mathrm{~min}$ at $90^{\circ} \mathrm{C}$. Both total and biotinylated proteins were resolved by SDS-PAGE, transferred to nitrocellulose membranes, and probed with anti-GluR1 C-terminal antibody (1:5000; Upstate Biotechnology, Lake Placid, NY), anti-GluR2/3 N-terminal antibody (1:1000; Chemicon, Temecula, CA) or anti- $\alpha$-actin antibody (1:1000; Chemicon), or anti-GluR6/7 (1:5000; Upstate Biotechnology). Immunoreactive bands were visualized by enhanced chemiluminescence, captured on autoradiography film (Eastman Kodak, Rochester, NY). Digital images were produced by densitometric scans of autoradiographs on a ScanJet 4300C (Hewlett Packard, Palo Alto, CA) and quantified using Scion (Frederick, MD) Image software. The surface/total protein ratio was calculated for each condition. When duplicate conditions were performed within one animal, the ratio values were averaged to obtain an animal average for that condition. Therefore, the $n$ values for the biotinylation experiments (see Figs. 4-6) represent the number of rats, as opposed to slices. Significant differences between surface/total ratios of treated slices and within-animal control slices were determined using a paired $t$ test (for ratio and $p$ values, see Table 1 ). Although the raw ratio values were used for statistical comparisons, the group data are presented in Figures 4-6 as a percentage of condition control to compare across different treatment conditions.

\section{Results}

\section{mGluR-LTD can be induced at immature synapses}

We first determined whether mGluR-LTD can be induced pharmacologically and synaptically at immature synapses. Hippocampal slices were prepared from neonatal (P8-P15) or adolescent (P21-P35) rats. Extracellular field potential recordings were obtained in area CA1 and were elicited by Schaffer collateral stimulation. LTD was induced using either the group $1 \mathrm{mGluR}$ agonist DHPG (100 $\mu \mathrm{M} ; 5 \mathrm{~min})$ or synaptic stimulation (900 pairs of stimulation pulses with a $50 \mathrm{~ms}$ interval delivered at $1 \mathrm{~Hz}$; 

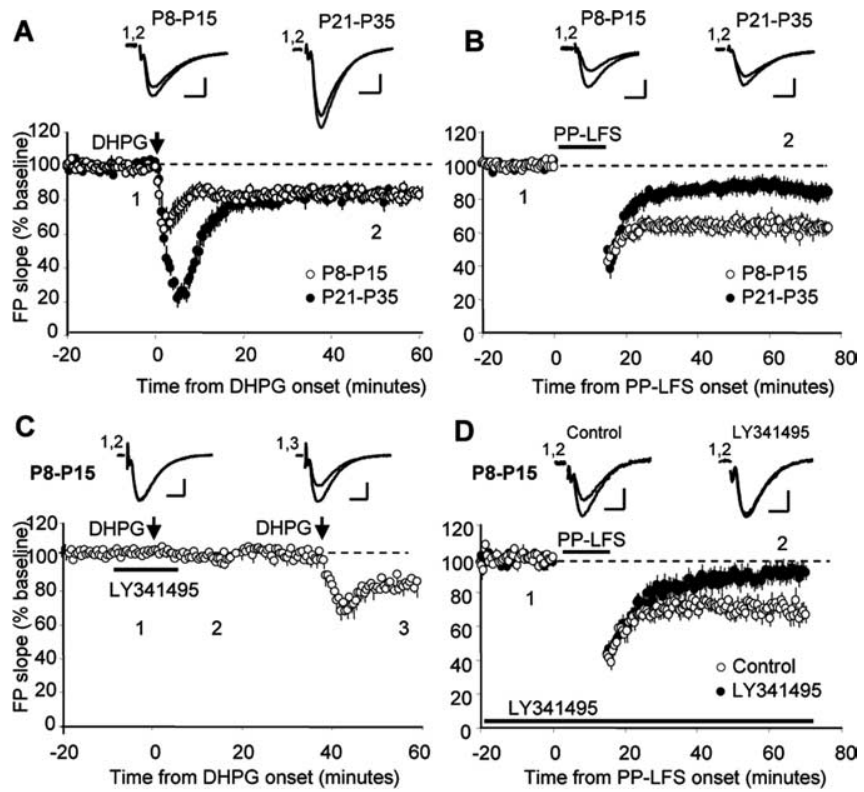

Figure 1. Chemically and synaptically induced mGluR-dependent LTD in neonatal hippocampus. All of the experiments shown in the figures were performed in the NMDA receptor antagonist D,L-AP-5 $(100 \mu \mathrm{M}) . \boldsymbol{A}-\boldsymbol{D}$, Plotted are FP slopes (mean \pm SEM) as a function of time from onset of DHPG or conditioning stimulation. $A$, DHPG ( $100 \mu \mathrm{m} ; 5 \mathrm{~min}$; arrow) induces LTD of FP slope values, which is similar in magnitude in neonatal (P8-P15) and adolescent (P21-P35) rats. $\boldsymbol{B}$, LTD induced with PP-LFS is enhanced in slices from neonatal rats compared with adolescent rats. C, DHPG-LTD in neonatal rats is blocked by the broad mGluR antagonist LY341495 $(100 \mu \mathrm{M})$. D, PP-LFS-induced LTD in neonatal rats is inhibited by LY341495 (100 $\mu \mathrm{M})$. Representative FPs (average, $1 \mathrm{~min}$ ) are shown for each experiment at the times indicated by the numbers on the graph. Calibration: $0.5 \mathrm{mV}, 5 \mathrm{~ms}$.

PP-LFS). Because the NMDAR-dependent form of LTD is robust at this developmental age (Dudek and Bear, 1993), all LTD experiments presented in this study were performed in the presence of the NMDAR antagonist D,L-AP-5 (100 $\mu \mathrm{M})$. We find that LTD can be induced in slices of neonatal rats with DHPG or PP-LFS in the presence of AP-5 (Fig. 1). Although group 1 mGluR function peaks during the early developmental period, DHPG-induced LTD is not enhanced at immature synapses $(83 \pm 3 \%$ of preDHPG baseline; $n=10$ ) compared with LTD in slices from adolescent rats $(84 \pm 4 \% ; n=7)$ (Fig. $1 A$ ). In contrast, LTD induced with PP-LFS is enhanced in slices from P8-P15 rats $(63 \pm 4 \%$; $n=6$ ) compared with P21-P35 rats ( $84 \pm 3 \% ; n=7 ; p<0.02$ ) (Fig. $1 B)$. Pretreatment of neonatal slices for $5 \mathrm{~min}$ in the broad $\mathrm{mGluR}$ antagonist (2S)-2-amino-2-[(1S,2S)-2-carboxycycloprop-1-yl]-3(xanth-9-yl) propanoic acid (LY341495) (100 $\mu \mathrm{M})$ (Fitzjohn et al., 1998) abolished DHPG-induced LTD (97 $\pm 2 \% ; n=6)$. In a subset of experiments, DHPG was applied after LY341495 washout and induced LTD (79 $\pm 4 \% ; n=3)$ (Fig. 1C). Preincubation (20-30 min) in LY341495 significantly reduced PP-LFS-induced LTD ( $92 \pm 5 \% ; n=7)$ compared with interleaved control slices $(68 \pm 6 \% ; n=11 ; p=0.004)$ (Fig. 1C). Although there was a slight residual depression observed with PP-LFS in LY341495, it was not significant compared with baseline values $(p=0.14)$. Our results indicate that an mGluR-dependent LTD can be induced in immature synapses by synaptic stimulation (PP-LFS) or DHPG.

\section{Developmental switch in the protein synthesis dependence of mGluR-LTD}

mGluR-LTD in adolescent rats (P21-P35) is dependent on dendritic protein synthesis and is independent of transcription $(\mathrm{Hu}-$
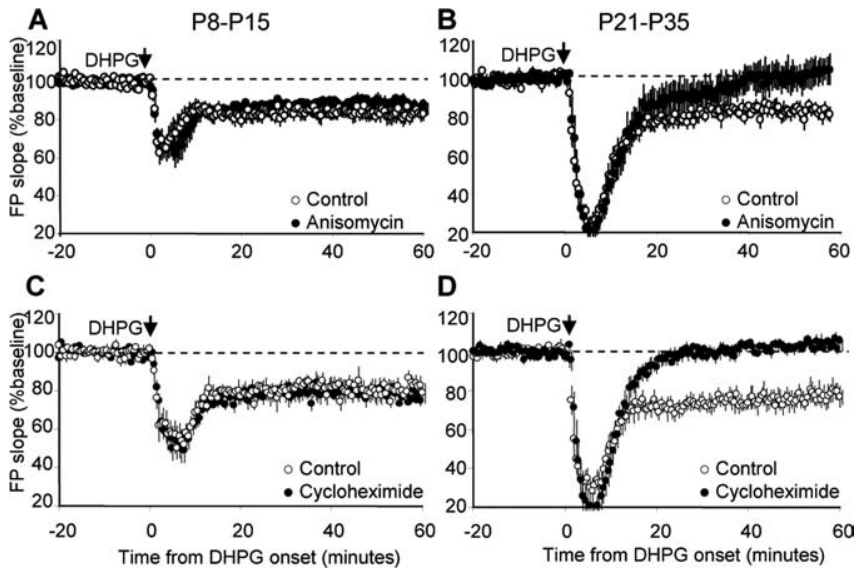

Figure 2. The protein synthesis dependence of chemically induced mGluR-LTD is developmentally regulated. $A, C, D H P G$-induced LTD in slices from neonatal rats is insensitive to the protein synthesis inhibitors anisomycin $(20 \mu \mathrm{m} ; \boldsymbol{A})$ or cycloheximide $(60 \mu \mathrm{m} ; \boldsymbol{C}) . \boldsymbol{B}, \boldsymbol{D}$, In contrast, anisomycin $(\boldsymbol{B})$ and cycloheximide (D) block DHPG-LTD in adolescent rats.

ber et al., 2000). Because numerous synaptic polyribosomes are observed at developing synapses (Steward and Falk, 1985, 1991), we hypothesized that mGluR-LTD at neonatal synapses would also be protein synthesis dependent. Surprisingly, we find that mGluR-LTD in neonatal rats is not sensitive to the protein synthesis inhibitors (Fig. 2). In neonatal rat slices, DHPG induced significant LTD in slices pretreated with anisomycin (88 $\pm 2 \%$; $n=10$ ) (Fig. $2 A$ ), which was not different from LTD in interleaved control slices ( $83 \pm 3 \% ; n=10 ; p=0.21$ ). The control DHPG-LTD values are the same data as those presented in Figure $1 A$ and were replotted in Figure $2 A$ for comparison with anisomycin-treated slices. In contrast, as reported previously, DHPG-induced LTD in adolescent rats was completely inhibited by anisomycin $(100 \pm 5 \%, n=6$; interleaved control slices, $84 \pm$ $3 \%, n=7 ; p=0.01$ ) (Fig. 2C). Similar results were observed with another protein synthesis inhibitor, cycloheximide $(60 \mu \mathrm{M})$. DHPG-LTD was completely blocked by cycloheximide in adolescent rats $(103 \pm 2 \%, n=4$; control slices, $77 \pm 5 \%, n=4 ; p=$ 0.01 ) (Fig. $2 D$ ) and was unaffected in neonatal rats ( $80 \pm 3 \%, n=$ 6; control slices, $81 \pm 3 \%, n=5 ; p=0.79$ ) (Fig. 2C). Likewise, LTD induced with synaptic stimulation (PP-LFS) only requires protein synthesis at mature synapses (P8-P15: control, $63 \pm 4 \%$, $n=6$; anisomycin, $60 \pm 5 \%, n=4$; P21-P35: control, $77 \pm 3 \%$, $n=18$; anisomycin, $99 \pm 4 \%, n=16 ; p=0.0001)$ (Fig. $3 A, B$ ). PP-LFS-induced LTD in neonatal rats was also insensitive to cycloheximide $(62 \pm 6 \%, n=8$; control slices, $64 \pm 2 \%, n=7 ; p=$ 0.01 ) (Fig. 3C) in contrast to adolescent rats (Huber et al., 2000).

Previous studies of mGluR-LTD in neonatal hippocampus have used $5 \mathrm{~Hz}$ synaptic stimulation ( $3 \mathrm{~min}$ ) (Bolshakov and Siegelbaum, 1994; Bolshakov et al., 2000; Zakharenko et al., 2002). Therefore, we also examined the protein synthesis dependence of mGluR-LTD using this protocol. As in LTD induced with DHPG and PP-LFS at this age, $5 \mathrm{~Hz}$-induced LTD was also insensitive to anisomycin (P8-P15: interleaved controls, $81 \pm$ $5 \%, n=7$; anisomycin, $78 \pm 4 \%, n=7 ; p=0.89$ ).

These results indicate that, as synapses mature, mGluR-LTD becomes increasingly dependent on protein synthesis. In support of this idea, the ability of anisomycin to block PP-LFS-induced LTD is significantly correlated with postnatal age $(r=0.53 ; p<$ 0.002) (Fig. 3D). 

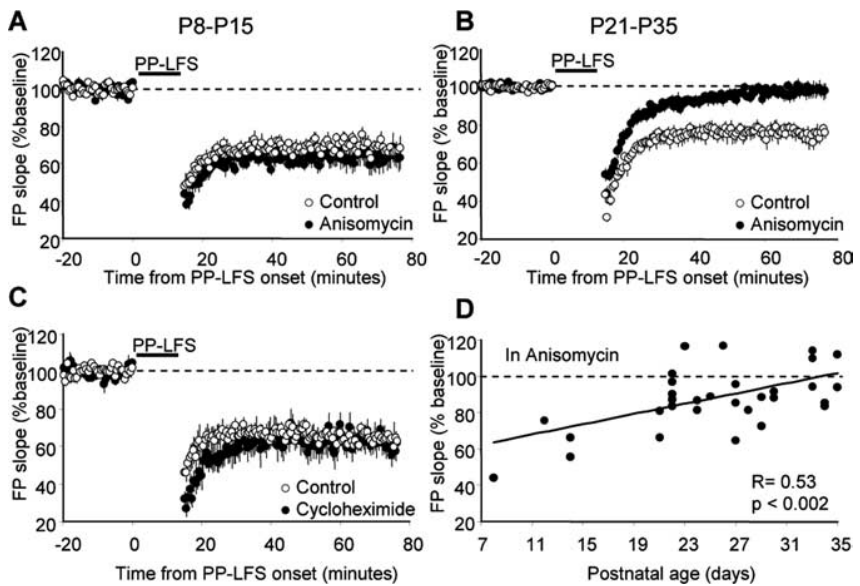

Figure 3. The protein synthesis dependence of synaptically induced mGluR-LTD is developmentally regulated. $A, C$, LTD induced with synaptic stimulation (PP-LFS) in neonatal rats is not affected by anisomycin $(\boldsymbol{A})$ or cycloheximide ( $\boldsymbol{C}$. $\boldsymbol{B}$, PP-LFS-induced LTD in slices from adolescent rats is blocked by anisomycin. $\boldsymbol{D}$, The ability of anisomycin to block PP-LFS-induced LTD is significantly correlated with the postnatal age of the rats.

\section{Developmental changes in mGluR-induced decreases in AMPAR surface expression}

In dissociated cultured neurons, activation of group $1 \mathrm{mGluRs}$ results in a long-term decrease in the surface expression of AMPARs and NMDARs, which requires protein synthesis (Snyder et al., 2001; Xiao et al., 2001). These results indicate that the new proteins required for mGluR-LTD most likely function to control AMPAR endocytosis or trafficking. Therefore, mGluRLTD at immature synapses may not be mediated by AMPAR internalization or there may be sufficient levels of protein(s) to maintain internalization in the absence of new synthesis.

To determine whether mGluR-dependent AMPAR endocytosis was developmentally regulated, we measured DHPG-induced changes in surface expression of AMPAR subunits GluR1 and GluR2/3. Previous studies of DHPG-induced AMPAR endocytosis have been performed in dissociated cultured hippocampal neurons (Snyder et al., 2001; Xiao et al., 2001). To correlate the developmental changes in mGluR-LTD with DHPG-induced AMPAR endocytosis in the same preparation, we performed these experiments in acute hippocampal slices using receptor biotinylation. We first verified that we could observe decreases in AMPAR surface expression in acute slices from adolescent rats. Slices were incubated in control ACSF or treated with DHPG (100 $\mu \mathrm{M} ; 5 \mathrm{~min}$ ). Surface receptors were labeled with biotin either 15 or 60 min after application of DHPG. Biotinylated receptors were precipitated, and the ratio of surface to total GluRs was determined by quantitative Western blotting. The biochemical analysis confirmed that DHPG treatment of hippocampal slices (P21-P35) results in a long-term (60 $\mathrm{min})$ decrease in biotinylated (surface)/total ratio of GluR2/3 (15 min after DHPG, $81 \pm$ $6 \%$ of control slices, $p=0.03, n=7 ; 60$ min after DHPG, $74 \pm$ $6 \%$ of control slices, $n=6, p=0.004$ ) (Fig. 4A) and GluR1 (15 min after DHPG, $81 \pm 4 \%, n=9, p=0.001 ; 60$ min after DHPG, $80 \pm 5 \%, n=6, p=0.018$ ) (Fig. $4 B$; for raw ratio values, see Table 1). DHPG did not affect the total levels of GluR2/3 (15 min, $99 \pm 3 \%$ of control, $p=0.87 ; 60 \mathrm{~min}, 103 \pm 12 \%, p=0.96)$ or GluR1 (15 min, $106 \pm 13 \%, p=0.4 ; 60 \mathrm{~min}, 101 \pm 22 \%, p=$ 0.78 ). As in mGluR-LTD, the DHPG-induced decreases in surface expression were blocked by the broad-range mGluR antagonist LY341495 (100 $\mu \mathrm{M}$; GluR1, 15 min after DHPG, $113 \pm$
A
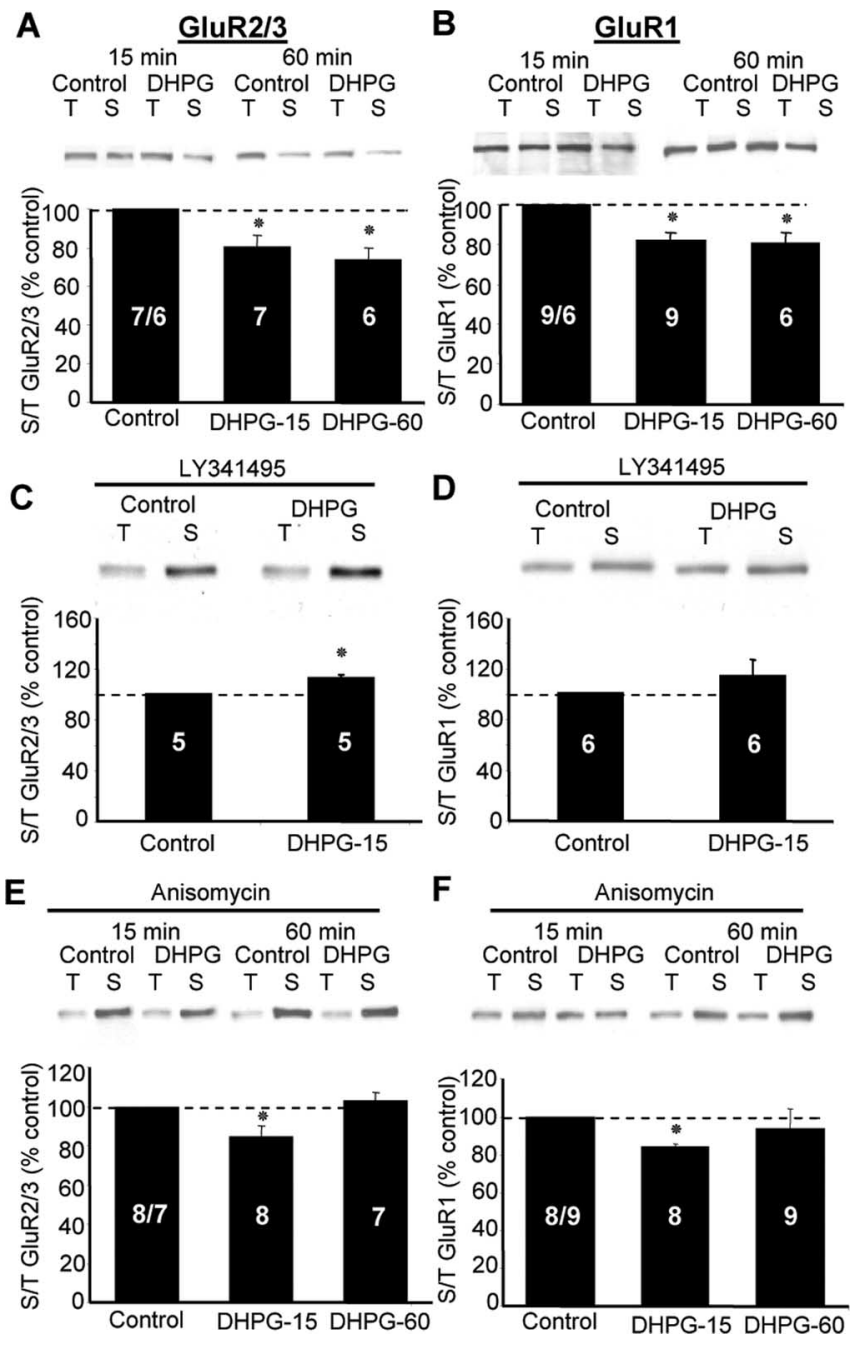

Figure 4. DHPG treatment of acute hippocampal slices from adolescent rats results in a protein synthesis-dependent decrease in AMPAR surface expression. $\boldsymbol{A}-\boldsymbol{F}$, Sample Western blots of total (T) and surface (S) GluR2/3 or GluR1 subunits of the AMPA receptor. Quantitative data of the ratio of surface to total GluR2/3 or GluR1 in hippocampal slices taken either 15 or 60 min after DHPG application (100 $\mu \mathrm{m} ; 5 \mathrm{~min}$ ). The number of experiments per group is indicated on each bar. ${ }^{*} p<0.05$. $A, B, D H P G$ treatment of hippocampal slices prepared from adolescent rats results in a long-term decrease of GluR2/3 and GluR1 surface expression using receptor biotinylation. C, D, Preincubation in the mGluR antagonist LY341495 (100 $\mu \mathrm{m})$ blocks DHPGinduced decreases in GluR2/3 and GluR1 surface expression. Quantitative data of the ratio of surface to total GluR2/3 or GluR1 in hippocampal slices taken 15 min after DHPG application (100 $\mu \mathrm{m} ; 5 \mathrm{~min}$ ) in the presence of LY341495. $\boldsymbol{E}, \boldsymbol{F}$, Preincubation of slices in the protein synthesis inhibitor anisomycin $(20 \mu \mathrm{M})$ specifically blocks the late (60 min) decrease in AMPAR surface expression induced by DHPG. Error bars represent SEM.

$12 \%, n=6, p=0.39$; GluR2/3, 15 min after DHPG, $113 \pm 3 \%$, $n=5, p=0.02$ ) (Fig. 4C,D).

As observed previously in neuronal culture, DHPG-induced decreases in AMPAR surface expression in hippocampal slices were sensitive to the protein synthesis inhibitor anisomycin $(20$ $\mu \mathrm{M})$. Slices preincubated in anisomycin displayed significantly reduced AMPAR surface expression at $15 \mathrm{~min}$ after DHPG treatment but not at $60 \mathrm{~min}$ after DHPG treatment (GluR2/3, $15 \mathrm{~min}$ after DHPG, $84 \pm 6 \%, n=8, p=0.036 ; 60$ min after DHPG, $102 \pm 5 \%, n=7, p=0.97$; GluR1, 15 min after DHPG, $84 \pm 1 \%$, $n=7, p=0.0003 ; 60$ min after DHPG, $94 \pm 10 \%, p=0.55, n=$ 9) (Fig. $4 E, F)$.

To determine whether the effects of DHPG are specific to the AMPA subtype of receptors, we measured changes in surface 
Table 1. Raw ratio values from surface biotinylation experiments

\begin{tabular}{|c|c|c|c|c|c|c|c|c|}
\hline \multirow[b]{2}{*}{$\begin{array}{r}\text { P21-P28 } \\
\text { DHPG } \\
\end{array}$} & \multicolumn{2}{|c|}{ Control (15 min) } & \multicolumn{2}{|c|}{ DHPG (15 min) } & \multicolumn{2}{|c|}{ Control (60 min) } & \multicolumn{2}{|c|}{ DHPG (60 min) } \\
\hline & GluR1 & GluR2/3 & GluR1 & GluR2/3 & GluR1 & GluR2/3 & GluR1 & GluR2/3 \\
\hline $\begin{array}{l}\text { Average } \\
\pm \text { SEM } \\
p \text { value (C vs D) }\end{array}$ & $\begin{array}{l}0.98064 \\
0.06544\end{array}$ & $\begin{array}{l}1.05308 \\
0.08330\end{array}$ & $\begin{array}{l}0.82407 \\
0.07955 \\
0.001\end{array}$ & $\begin{array}{l}0.81229 \\
0.04496 \\
0.037\end{array}$ & $\begin{array}{l}0.89515 \\
0.06765\end{array}$ & $\begin{array}{l}0.97139 \\
0.02910\end{array}$ & $\begin{array}{l}0.71148 \\
0.05018 \\
0.018\end{array}$ & $\begin{array}{l}0.72411 \\
0.06829 \\
0.004\end{array}$ \\
\hline $\begin{array}{l}\text { DHPG + LY341495 } \\
\text { Average } \\
\pm \text { SEM } \\
p \text { value (C vs D) }\end{array}$ & $\begin{array}{l}1.465 \\
0.18267\end{array}$ & $\begin{array}{l}2.26206 \\
0.15174\end{array}$ & $\begin{array}{l}1.57413 \\
0.09805 \\
0.396\end{array}$ & $\begin{array}{l}2.52389 \\
0.19911 \\
0.019\end{array}$ & & & & \\
\hline $\begin{array}{l}\text { DHPG + anisomycin } \\
\text { Average } \\
\pm \text { SEM } \\
p \text { value (C vs D) }\end{array}$ & $\begin{array}{l}1.45712 \\
0.06818\end{array}$ & $\begin{array}{l}1.83231 \\
0.22425\end{array}$ & $\begin{array}{l}1.22874 \\
0.06135 \\
0.0003\end{array}$ & $\begin{array}{l}1.5376 \\
0.18412 \\
0.036\end{array}$ & $\begin{array}{l}1.33823 \\
0.10930\end{array}$ & $\begin{array}{l}1.66739 \\
0.20475\end{array}$ & $\begin{array}{l}1.27050 \\
0.07333 \\
0.545\end{array}$ & $\begin{array}{l}1.67365 \\
0.17433 \\
0.971\end{array}$ \\
\hline & Control (1 & & & & & & & \\
\hline & GluR6/7 & & DHPG $(15$ & & Control ( & & DHPG $(6$ & \\
\hline DHPG & & & & & & & & \\
\hline $\begin{array}{l}\text { Average } \\
\pm \text { SEM } \\
p \text { value (Cvs D) }\end{array}$ & $\begin{array}{l}1.16842 \\
0.12543\end{array}$ & $G(\Psi) B>13$ & $\begin{array}{l}1.12597 \\
0.06925 \\
0.774\end{array}$ & $G(\mu R>1 /$ & $\begin{array}{l}1.36938 \\
0.09599\end{array}$ & 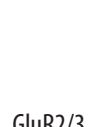 & $\begin{array}{l}1.27861 \\
0.12432 \\
0.575\end{array}$ & 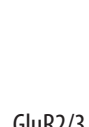 \\
\hline $\begin{array}{c}\text { P8-P15 } \\
\text { DHPG }\end{array}$ & & & & & & & & \\
\hline $\begin{array}{l}\text { Average } \\
\pm \text { SEM } \\
p \text { value (C vs D) }\end{array}$ & $\begin{array}{l}0.97704 \\
0.03661\end{array}$ & $\begin{array}{l}1.14853 \\
0.10182\end{array}$ & $\begin{array}{l}0.96672 \\
0.04249 \\
0.777\end{array}$ & $\begin{array}{l}1.12262 \\
0.10879 \\
0.799\end{array}$ & $\begin{array}{l}0.91064 \\
0.03961\end{array}$ & $\begin{array}{l}1.21573 \\
0.15425\end{array}$ & $\begin{array}{l}1.01075 \\
0.02936 \\
0.003\end{array}$ & $\begin{array}{l}1.25699 \\
0.13037 \\
0.691\end{array}$ \\
\hline & Control (1 & & NMDA (1 & & Control ( & & NMDA (C & \\
\hline & GluR1 & GluR2/3 & GluR1 & GluR2/3 & GluR1 & GluR2/3 & GluR1 & GluR2/3 \\
\hline NMDA & & & & & & & & \\
\hline $\begin{array}{l}\text { Average } \\
\pm \text { SEM } \\
p \text { value (Cvs N) }\end{array}$ & $\begin{array}{l}2.54 \\
0.231\end{array}$ & $\begin{array}{l}2.382 \\
0.192\end{array}$ & $\begin{array}{l}2.099 \\
0.229 \\
0.00007\end{array}$ & $\begin{array}{l}1.714 \\
0.092 \\
0.033\end{array}$ & $\begin{array}{l}2.207 \\
0.071\end{array}$ & $\begin{array}{l}2.31 \\
0.218\end{array}$ & $\begin{array}{l}1.679 \\
0.160 \\
0.008\end{array}$ & $\begin{array}{l}2.052 \\
0.172 \\
0.028\end{array}$ \\
\hline
\end{tabular}

Average \pm SEM ratios of surface (biotinylated)/total protein from experiments presented in Figures 4-6. $p$ values are from a paired $t$ test comparing data from DHPG-treated (D) or NMDA-treated (N) samples with within-animal controls (C).

expression of kainate receptor subunits GluR6 and GluR7. In area CA1, kainate receptors are expressed primarily presynaptically on both excitatory and inhibitory synapses and postsynaptically on interneurons (Huettner, 2003). DHPG did not affect the surface expression of GluR6/7 ( 15 min after DHPG, $100 \pm 10 \%, p=$ $0.77, n=6 ; 60$ min after DHPG, $93 \pm 5 \%, p=0.58, n=7$ ) (Fig. $5 A$ ), indicating that DHPG causes a specific reduction in AMPAR surface expression. Additional control experiments confirmed that intracellular proteins, such as actin, were not biotinylated in this assay $(n=3)$ (Fig. $5 B)$. Together, these experiments confirm that DHPG causes an mGluR- and protein synthesis-dependent long-term decrease in AMPAR surface expression in acute slices from adolescent rats.

In contrast to adolescent rats, DHPG treatment of slices from neonatal animals did not decrease the surface expression of GluR2/3 and GluR1 subunits (GluR2/3: 15 min after DHPG, $98 \pm 5 \%, n=10, p=0.8 ; 60$ min after DHPG, $104 \pm 5 \%, n=12$, $p=0.69$; GluR1: 15 min DHPG, $100 \pm 4 \%, n=9 ; 60$ min after DHPG, $111 \pm 4 \%, p=0.003, n=10$ ) (Fig. $6 A, B$ ).

In addition to mGluRs, chemical activation of NMDARs induces LTD and internalization of AMPARs (Lee et al., 1998; Colledge et al., 2003). We performed additional experiments, treating neonatal slices with NMDA to determine whether there is a general deficit in activity-induced AMPAR internalization in neonatal slices or whether the deficit is specific for the mGluR

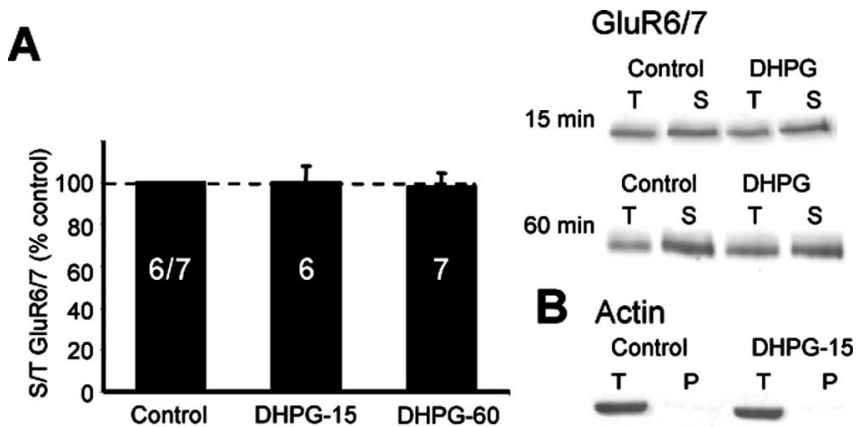

Figure 5. DHPG does not affect the surface expression of kainate receptors in adolescent rats. A, Sample Western blot of total (T) and surface (S) GluR6/7. Quantitative data of the ratio of surface to total GluR6/7 in hippocampal slices taken either 15 or 60 min after DHPG application (100 $\mu \mathrm{m} ; 5 \mathrm{~min}$ ). The number of experiments per group is indicated on each bar. $\boldsymbol{B}$, Sample Western blot of total actin and actin "pulled down" (P) with avidin beads, demonstrating that intracellular proteins are not biotinylated in this assay. Error bars represent SEM.

pathway. We first confirmed that NMDA ( $20 \mu \mathrm{M} ; 3 \mathrm{~min})$ induced LTD in CA1 of neonatal hippocampal slices ( $80 \pm 3 \%$ of baseline at 55-60 min after NMDA application; $n=5$ ). Unlike DHPG treatment of neonatal slices, we observed decreases in surface expression of GluR1 and GluR2/3 at $10 \mathrm{~min}$ (GluR1, $82 \pm 2 \%$ of control slices; $n=6, p<0.001$; GluR2/3, $74 \pm 6 \%, n=5, p=$ 

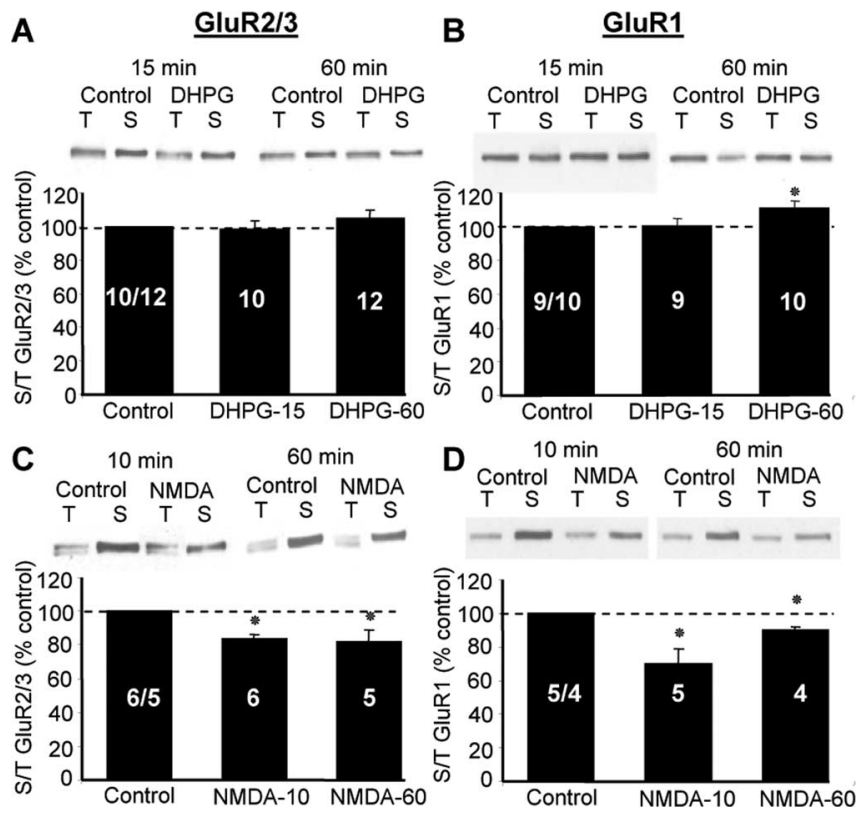

Figure 6. NMDAR activation, but not mGluR activation, reduces AMPAR surface expression in neonatal rat slices. A, Sample Western blot of total (T) and surface (S) GluR2/3. Quantitative data of the ratio of surface to total GluR2/3 in hippocampal slices taken either 15 or 60 min after DHPG application (100 $\mu \mathrm{m} ; 5 \mathrm{~min})$. The number of experiments per group is indicated on each bar. ${ }^{*} p<0.05$. B, Sample Western blot of GluR1 and quantitative data of the same samples as those used in $\boldsymbol{A}$. C, Sample Western blot and quantitative data of the ratio of surface to total GluR2/3 in hippocampal slices taken either 10 or 60 min after NMDA application ( $20 \mu \mathrm{m} ; 3 \mathrm{~min}$ ). D, Sample Western blot of GluR1 and quantitative data of the same samples as those used in $\boldsymbol{C}$ Error bars represent SEM.

$0.03)$ and $60 \min ($ GluR1, $75 \pm 5 \%, n=5, p=0.008$; GluR2/3, $89 \pm 2 \%, n=4, p=0.02)$ after NMDA $(20 \mu \mathrm{M} ; 3 \mathrm{~min})$ application (Fig. 6C,D; Table 1). These data demonstrate that mGluRinduced, but not NMDA-induced, decreases in AMPAR surface expression are developmentally regulated and do not occur at immature synapses. This finding also suggests that mGluR-LTD at this age is not mediated by a decrease in postsynaptic receptor number.

\section{Presynaptic changes accompany mGluR-LTD at neonatal synapses}

Previous studies of mGluR-LTD in slices from young (P4-P18) rats show strong evidence that LTD expression is mediated by a long-term decrease in presynaptic function (Bolshakov and Siegelbaum, 1994; Fitzjohn et al., 2001; Zakharenko et al., 2002; Rammes et al., 2003). Therefore, based on these studies and our findings that mGluR-dependent decreases in AMPAR surface expression are only observed in adolescent rats, we propose that there is a developmental change in the synaptic mechanisms of mGluR-LTD expression. To test this idea, we used two parameters to measure changes in presynaptic release probability during LTD, PPF, and the rate of blockade of NMDA receptor-mediated synaptic responses by MK801. These parameters were measured after DHPG-induced LTD in slices from both neonatal (P8-P15) and adolescent (P21-P35) rats. DHPG-induced LTD was examined, as opposed to synaptically induced LTD, because a similar magnitude of DHPG-induced LTD is observed across these developmental ages (Figs. 1A, 7B) and would allow comparison of the degree of PPF changes or rate of MK801 blockade across development.

Manipulations that alter presynaptic release probability, such

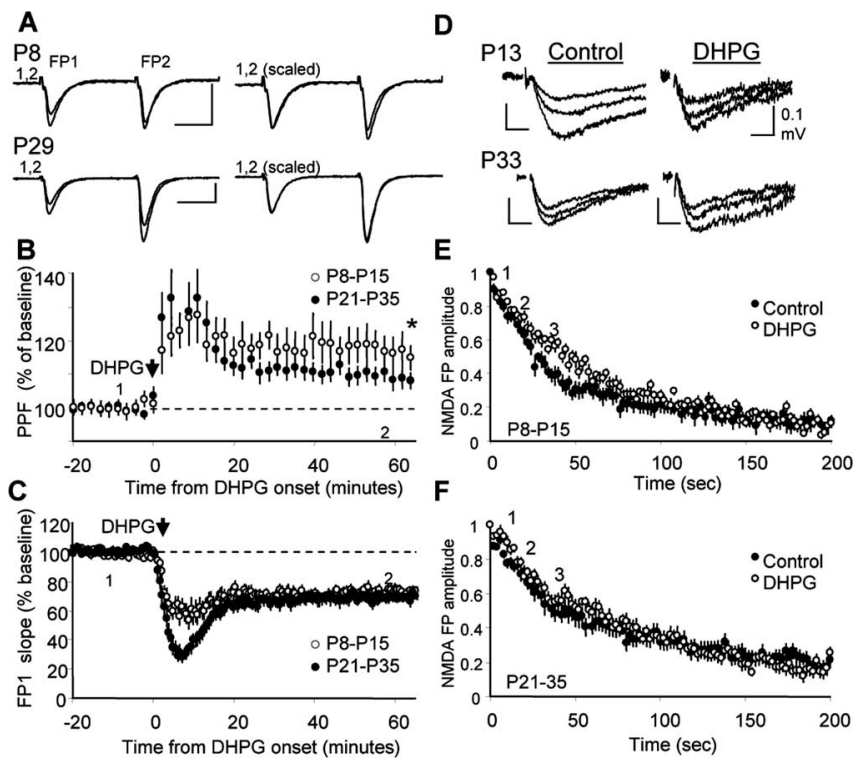

Figure 7. mGluR-LTD in neonatal rats is associated with changes in presynaptic function. $A$, Representative FPs elicited by paired-pulse stimulation in P8 -P15 and P21-P35 hippocampal slices during baseline (1) and after 50 min of DHPG onset (2). Calibration: $0.5 \mathrm{mV}, 20 \mathrm{~ms}$. DHPG trace (2) was scaled to baseline FP1 amplitude for comparison of PPF changes within a single experiment. Note that, in the P8 rat, the second response is facilitated but is unchanged at $\mathrm{P} 29$. $B$, Group data of PPF (FP2 slope/FP1 slope as a percentage of pre-DHPG baseline) change during LTD in neonatal and adolescent animals. The asterisk indicates that PPF changes are greater in neonatal than adolescent rats $(p<0.02)$. C, DHPG-induced LTD of FP1 was not different among age groups. $\boldsymbol{D}$, Representative NMDAR FPs taken at the times indicated in $\boldsymbol{E}$ and $\boldsymbol{F}$ from a P13 or P33 rat. Calibration: 0.2 or $0.1 \mathrm{mV}$ (as indicated), $10 \mathrm{~ms}$. $E, F$, Group average of decay of NMDAR FP amplitude in the presence of MK801 (10 $\mu \mathrm{M})$ in control or after DHPG (100 $\mu \mathrm{m} ; 5$ $\mathrm{min}$ ) treatment of neonatal $(\boldsymbol{E})$ or adolescent $(\boldsymbol{F})$ rat slices. Fast component $(\tau 1)$ is slower in DHPG-treated neonatal slices.

as decreases in the $\mathrm{Ca}^{2+} / \mathrm{Mg}^{2+}$ ratio or adenosine, increase paired-pulse facilitation. Generally, the magnitude of PPF is inversely related to presynaptic release probability (Creager et al., 1980; Manabe et al., 1993; Debanne et al., 1996). However, preferential postsynaptic "silencing" of high- or low-release probability synapses also result in PPF changes (Poncer and Malinow, 2001). Pairs of stimulation (interstimulus interval, $50 \mathrm{~ms}$ ) were delivered during baseline stimulation, during DHPG application, and for $1 \mathrm{~h}$ after DHPG. In slices from neonatal rats, PPF ratios increased during DHPG application and persisted for at least 60 min after DHPG $(116 \pm 2 \%$ of pre-DHPG baseline PPF values; $n=14 ; p<0.0001$ ), as reported previously (Fitzjohn et al., 2001). PPF values also increased during LTD in slices from adolescent rats $(109 \pm 2 \%$ of pre-DHPG baseline; $n=24 ; p=0.008)$. However, the PPF increases in neonatal animals were significantly greater than those observed in adolescent rats $(p<0.02)$ (Fig. 7A). There was no difference in the magnitude of DHPGinduced LTD $(\mathrm{P} 8-\mathrm{P} 15,72 \pm 2 \%, n=14$; P21-P35, $69 \pm 2 \%, n=$ $24 ; p=0.4$ ) (Fig. $7 C$ ) or the absolute levels of PPF [P8-P15, $1.63 \pm 0.05$ (FP2/FP1 slope); P21-P35, $1.59 \pm 0.05 ; p=0.63]$ between these developmental ages. To further support a developmental change in the presynaptic contribution to mGluR-LTD, there is an inverse correlation of PPF changes during LTD and postnatal age $(r=0.4 ; p<0.01)$.

As another means to measure developmental changes in presynaptic function associated with LTD, we used the irreversible, use-dependent NMDAR antagonist MK801. During repetitive presynaptic stimulation, the rate of blockade of NMDAR responses by MK801 has been used to determine presynaptic re- 
lease probability $\left(P_{\mathrm{r}}\right)$ and detect changes in $P_{\mathrm{r}}$ during long-term plasticity, such as long-term potentiation and LTD (Hessler et al., 1993; Rosenmund et al., 1993; Weisskopf and Nicoll, 1995; Kullmann et al., 1996; Xiao et al., 1997; Kaneko and Takahashi, 2004). If $P_{\mathrm{r}}$ is relatively high, there is a greater number of NMDAR channels opened and a more rapid blockade of the response by MK801. We compared the rate of MK801 blockade of NMDARmediated FPs in control slices and those in which LTD had been induced using DHPG from both neonatal and adolescent rats. DHPG was used to induce LTD in normal ACSF. After LTD (of the AMPAR response) was established (30 min after DHPG application), a modified ACSF (see Materials and Methods) was applied to the slice to isolate the NMDAR-mediated FP, and this response was allowed to stabilize $(\sim 20-25 \mathrm{~min})$. Synaptic stimulation was stopped for $10 \mathrm{~min}$, and MK801 $(10 \mu \mathrm{M})$ was applied to the slice. Synaptic stimulation (200 pulses) was resumed at 0.5 $\mathrm{Hz}$ in the presence of MK801. The rate of decay of the NMDAR FP amplitude by MK801 was fit by a double exponential, and time constants for the fast $(\tau 1)$ and slow $(\tau 2)$ components were obtained (Fig. 7 E,F) (Rosenmund et al., 1993). These two components are thought to represent two populations of synaptic terminals with a high and low $P_{\mathrm{r}}$ (Rosenmund et al., 1993). In neonatal slices, DHPG caused an increase in $\tau 1$ (DHPG, $\tau 1,49 \pm$ $8 \mathrm{~s}$; control, $\tau 1,26 \pm 3 \mathrm{~s} ; n=6 ; p=0.02)$, consistent with a lower $P_{\mathrm{r}}$ after DHPG treatment. This change was evident by the slower decay curves in DHPG-treated slices (Fig. 7E). In contrast, DHPG treatment of adolescent slices did not significantly affect $\tau 1$, and the decay curves overlapped (DHPG, $\tau 1,49 \pm 8 \mathrm{~s}$; control, $\tau 1$, $33 \pm 8 \mathrm{~s} ; n=6 ; p=0.19$ ) (Fig. $7 F)$. There was no change in $\tau 2$ at either age (neonatal: DHPG, $\tau 2,222 \pm 22 \mathrm{~s}$; control, $\tau 2,178 \pm$ $21 \mathrm{~s} ; n=6 ; p=0.15$; adolescent: DHPG, $\tau 2,188 \pm 24$ s; control, $\tau 2,254 \pm 35 \mathrm{~s} ; n=6 ; p=0.11)$. There were no differences in $\tau 1$ or $\tau 2$ between the neonatal and adolescent groups ( $p=0.45$ and 0.1 , respectively). These results, together with the observed PPF changes during LTD, confirm that mGluR-LTD at neonatal synapses is accompanied by decreases in presynaptic release probability (Bolshakov and Siegelbaum, 1994; Fitzjohn et al., 2001; Zakharenko et al., 2002). Our results also indicate that the magnitude of these presynaptic changes diminish as synapses mature and suggest that other, perhaps postsynaptic, mechanisms contribute to mGluR-LTD in mature synapses.

\section{$\mathrm{CB}_{1}$ receptor activation is not required for $\mathrm{mGluR}-\mathrm{LTD}$ in neonatal rats}

Previous work has demonstrated that the induction of mGluRLTD at neonatal synapses requires postsynaptic $\mathrm{Ca}^{2+}$ influx and depolarization (Bolshakov and Siegelbaum, 1994; Oliet et al., 1997). Because of the presynaptic changes associated with LTD, the existence of a retrograde messenger has been postulated. Here, we tested the involvement of potential retrograde messengers in mGluR-LTD at neonatal synapses: endocannabinoids.

Endocannabinoids are released from CA1 pyramidal neurons in response to group $1 \mathrm{mGluR}$ activation and depress both excitatory and inhibitory synaptic transmission via a presynaptic $\mathrm{CB}_{1} \mathrm{R}$ (Misner and Sullivan, 1999; Varma et al., 2001; OhnoShosaku et al., 2002). Endocannabinoids have also been implicated in LTD at inhibitory synapses in area CA1 and at excitatory synapses in the basal ganglia and neocortex (Gerdeman et al., 2002; Robbe et al., 2002; Chevaleyre and Castillo, 2003; Sjostrom et al., 2003). A previous study failed to find a role for $\mathrm{CB}_{1} \mathrm{R}$ in DHPG-induced LTD in area CA1 of adolescent mice (Rouach and Nicoll, 2003). We obtained similar results in neonatal rat hippocampal slices and found no role for $\mathrm{CB}_{1} \mathrm{R}$ in mGluR-LTD

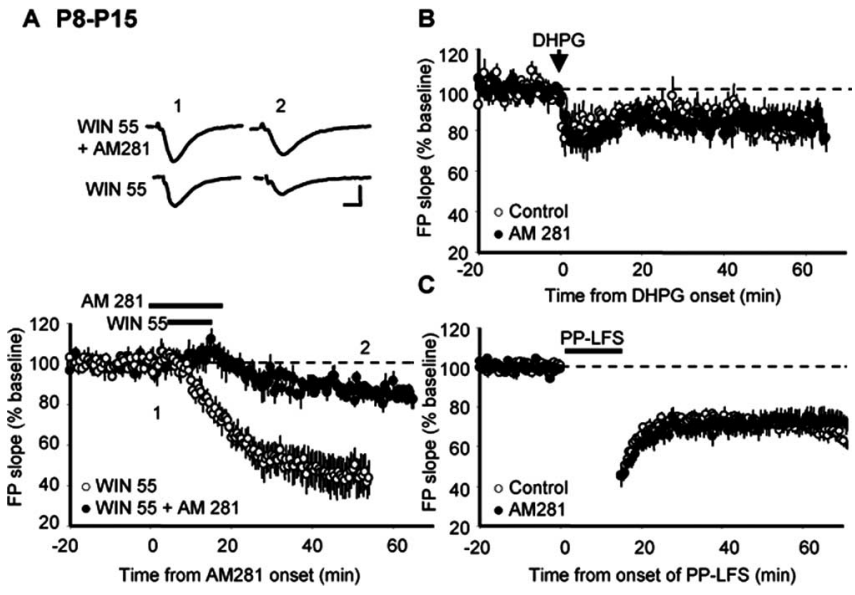

Figure 8. $\quad \mathrm{CB}_{1}$ R activation is not required for $m G$ luR-LTD in neonatal slices. $A, C B_{1} R$ antagonist AM281 $(1 \mu \mathrm{M})$ is effective in the hippocampal slice preparation and inhibits synaptic depression induced by a brief application of the $\mathrm{CB}_{1} \mathrm{R}$ agonist WIN55,212-2 (WIN 55; $2 \mu \mathrm{m} ; 10$ $\mathrm{min})$. Solid bars indicate the time of drug application. Representative FPs are taken at the times indicated by the numbers on the graph. Calibration: $0.5 \mathrm{mV}, 5 \mathrm{~ms}$. B, C, Preincubation in AM281 does not affect LTD induced with DHPG $(\boldsymbol{B})$ or PP-LFS $(\boldsymbol{C})$ in neonatal rat slices.

(Fig. $8 B, C$ ). The effects of the $\mathrm{CB}_{1} \mathrm{R}$ antagonist AM281 $(1 \mu \mathrm{M})$ were tested on mGluR-LTD in neonatal slices, which blocks mGluR and depolarization-induced endocannabinoid release (Gifford et al., 1997; Maejima et al., 2001; Ohno-Shosaku et al., 2002; Melis et al., 2004). AM281 (1 $\mu \mathrm{M})$ had no effect on either DHPG-induced LTD (AM281, $84 \pm 6 \%, n=7$; control, $84 \pm$ $4 \%, n=7 ; p=0.94$ ) or LTD induced with PP-LFS (AM281, $73 \pm$ $5 \%, n=8$; control, $67 \pm 3 \%, n=10 ; p=0.26)$. In contrast, preapplication of AM281 greatly reduced the synaptic depression induced by the $\mathrm{CB}_{1} \mathrm{R}$ agonist WIN55,212-2 (2 $\left.\mu \mathrm{M} ; 10 \mathrm{~min}\right)$ (D'Ambra et al., 1992; Al-Hayani and Davies, 2000), indicating that the antagonist is effective in our slice preparation (WIN55,212-2, $47 \pm 9 \%$ of baseline, $n=4$; WIN55,212-2 plus AM281, $87 \pm 2 \%, n=4 ; p=0.03$ ) (Fig. $8 A$ ). These results confirm that $\mathrm{CB}_{1} \mathrm{R}$ activation depresses excitatory synaptic transmission in neonatal hippocampal area CA1 (Al-Hayani and Davies, 2000) and demonstrate that $\mathrm{CB}_{1}$ Rs are not required for mGluR-induced LTD at this age.

\section{Discussion}

Here, we show, using both pharmacological and synaptic stimulation of group $1 \mathrm{mGluRs}$, that the synaptic mechanisms and protein synthesis dependence of mGluR-LTD change with developmental age. In neonatal synapses, mGluR-LTD does not rely on protein synthesis and is associated with large changes in PPF and the rate of MK801 blockade, suggesting a presynaptic site of LTD expression. Consistent with this idea, mGluR activation of neonatal slices does not cause a decrease in AMPAR surface expression. As synapses mature, mGluR-LTD and the associated decrease in AMPAR surface expression require new protein synthesis and result in a small or no change in presynaptic function.

Previous studies on the synaptic mechanisms of mGluR-LTD have yielded conflicting results. Many of the studies, which concluded there is a presynaptic site of mGluR-LTD expression, were performed in hippocampal slices from neonatal animals (P4P18) (Bolshakov and Siegelbaum, 1994; Fitzjohn et al., 2001; Zakharenko et al., 2002; Rammes et al., 2003) (but see Watabe et al., 2002). However, the studies demonstrating a role for postsynaptic protein synthesis were performed at more mature synapses (14-21 d in vitro cultures or slices from P10-P30 rats) (Huber et 
al., 2000; Snyder et al., 2001; Xiao et al., 2001). Our results offer an explanation for these disparate results and indicate that the developmental state of the synapse determines its response to postsynaptic mGluR activation.

To quantitate and compare the developmental changes in LTD, we grouped our data into two age groups: neonatal (P8P15) and adolescent (P21-P35). However, the significant correlations of postnatal age with the effects of anisomycin on LTD (Fig. 3D) and the magnitude of PPF changes associated with LTD suggest that synaptic changes in mGluR-LTD do not occur abruptly but gradually as the synapses mature. Furthermore, the fact that there are small changes in PPF (Fig. 7B) and a nonsignificant reduction in $\tau 1$ of MK801 blockade, which occur during LTD in the adolescent group, suggest that a presynaptic expression mechanism, albeit reduced, may persist at mature synapses. However, because mGluR-LTD in adolescents is blocked by protein synthesis inhibitors, this suggests that any presynaptic contribution must also require protein synthesis. Alternatively, or in addition, PPF changes observed in the adolescent group may have a contribution from AMPAR removal at high release probability synapses (Poncer and Malinow, 2001).

There are alternative explanations for the greater PPF changes we observe during LTD at neonatal synapses. A recent study demonstrated that the baseline PPF magnitude is inversely correlated with the PPF changes observed during LTD (Santschi and Stanton, 2003). Therefore, a higher $P_{\mathrm{r}}$ at neonatal synapses would be reflected by a lower PPF and could explain why there are greater increases in PPF during LTD. In our study, we find no correlation with baseline PPF and the change in PPF with LTD $(r=0.05 ; p=$ $0.7)$. The difference in our findings may be attributable to a difference in the route of LTD induction (Santschi and Stanton, 2003). Furthermore, we do not find a correlation with developmental age and the baseline PPF $(r=0.13 ; p=0.4)$ or differences in the average baseline PPF values or the $\tau 1$ of MK801 blockade between neonatal and adolescent groups (see Results). A recent study described developmental decreases in $P_{\mathrm{r}}$ at hippocampal synapses, as measured by PPF and the rate of MK801 blockade, but these changes occurred during an earlier developmental window (from P6 to P12) than our developmental switch (Wasling et al., 2004). Other studies of $P_{\mathrm{r}}$ later in hippocampal development (P15-P35) report an increase in $P_{\mathrm{r}}$ or no change (Dumas and Foster, 1995; Hsia et al., 1998). We think that the greater DHPGinduced changes in PPF and rate of MK801 blockade at neonatal synapses represent a greater presynaptic contribution to the LTD compared with more mature synapses.

Although we find that mGluR-LTD is independent of protein synthesis at developing synapses, our results do not address the question of whether mGluRs activate synaptic protein synthesis at this age. Instead, our data indicate that there are developmental changes in mGluR regulation of AMPAR trafficking. New proteins are required for the persistent decrease in surface AMPAR expression at mature synapses (Fig. 4E,F) (Snyder et al., 2001). Therefore, it is likely that LTD is protein synthesis independent in the neonatal slices because mGluR activation does not alter AMPAR surface expression (Fig. 6). Because NMDAR-dependent decreases in AMPAR surface expression are intact in neonatal synapses, we conclude that components of the mGluR-mediated AMPAR endocytosis process are developmentally regulated, as opposed to general AMPAR endocytosis machinery.

We measured changes in GluR surface expression and not endocytosis per se. Therefore, mGluR activation of neonatal synapses may induce endocytosis of AMPARs but also increase insertion rates so there is no net change in surface expression. In addition, with receptor biotinylation, we cannot determine whether we are measuring surface expression of synaptic or extrasynaptic receptors or both. Therefore, the developmental differences that we observe in DHPG-induced decreases in AMPAR surface expression could be attributable to a difference in the ability to detect surface changes in synaptic receptors with biotinylation. Using immunocytochemistry in dissociated neuronal culture, DHPG has been shown to reduce the number of synaptic AMPARs associated with presynaptic markers, and we would predict that similar changes are occurring in the slice (Snyder et al., 2001). However, it remains to be determined whether there is a developmental change in the effects of DHPG specifically on synaptic AMPARs. Recent work demonstrated that postsynaptic $\mathrm{Ca}^{2+}$ increases alone, independent of NMDARs or mGluRs, are sufficient to induce "silent" synapses (presumably by removing postsynaptic AMPARs) at immature (P3-P12), but not mature (P29-P32), synapses (Xiao et al., 2004). This previous work and our current results suggest that the mechanisms that induce AMPAR removal, such as those that regulate insertion, change with synapse development (Esteban et al., 2003; Yasuda et al., 2003).

The $\mathrm{CB}_{1} \mathrm{R}$ agonist WIN55,212-2 induced a small depression in the presence of $1 \mu \mathrm{M}$ AM281 (Fig. $8 A$ ), suggesting an incomplete blockade of $\mathrm{CB}_{1}$ Rs. This leaves open the possibility that a minority of $\mathrm{CB}_{1} \mathrm{R}$ activation can lead to full mGluR-LTD. However, we find this unlikely and think that our results are consistent with those of Rouach and Nicoll (2003) (from mature rats), who found no role for endocannabinoids in mGluR-LTD of excitatory synaptic transmission. Because endocannabinoids have been implicated in mGluR-dependent LTD of inhibitory synaptic transmission (Chevaleyre and Castillo, 2003), this suggests that mGluRs use distinct mechanisms to induce LTD of inhibitory and excitatory synaptic transmission. Another potential retrograde messenger for mGluR-LTD at immature synapses is the arachidonic acid metabolite 12-( $S$ )hydroperoxyeicosatetraenoic acid, which is required for mGluR-LTD induced with $5 \mathrm{~Hz}$ stimulation (Feinmark et al., 2003). Additional experiments are required to confirm the role of arachidonic acid metabolism in DHPG and PP-LFS-induced LTD.

The developmental switch in the synaptic mechanisms of LTD may occur to accommodate the changing properties of synapses over the course of maturation. Because there are fewer surface AMPARs at immature synapses (Liao et al., 1999; Petralia et al., 1999; Pickard et al., 2000), it may be more efficacious to depress synaptic transmission at developing synapses by reducing presynaptic release probability, as opposed to endocytosis of AMPARs. The consequences of the developmental switch of LTD on hippocampal function are unclear. Because mGluR-LTD affects the short-term dynamics of nascent synapses (Fig. 7), it may differentially impact information processing and plasticity of developing and mature CA1 synapses (Fuhrmann et al., 2002).

\section{References}

Al-Hayani A, Davies SN (2000) Cannabinoid receptor mediated inhibition of excitatory synaptic transmission in the rat hippocampal slice is developmentally regulated. Br J Pharmacol 131:663-665.

Bolshakov VY, Siegelbaum SA (1994) Postsynaptic induction and presynaptic expression of hippocampal long-term depression. Science 264:1148-1152.

Bolshakov VY, Siegelbaum SA (1995) Regulation of hippocampal transmitter release during development and long-term potentiation. Science 269:1730-1734.

Bolshakov VY, Carboni L, Cobb MH, Siegelbaum SA, Belardetti F (2000) Dual MAP kinase pathways mediate opposing forms of long-term plasticity at CA3-CA1 synapses. Nat Neurosci 3:1107-1112. 
Casabona G, Knopfel T, Kuhn R, Gasparini F, Baumann P, Sortino MA, Copani A, Nicoletti F (1997) Expression and coupling to polyphosphoinositide hydrolysis of group I metabotropic glutamate receptors in early postnatal and adult rat brain. Eur J Neurosci 9:12-17.

Chevaleyre V, Castillo PE (2003) Heterosynaptic LTD of hippocampal GABAergic synapses: a novel role of endocannabinoids in regulating excitability. Neuron 38:461-472.

Chung HJ, Xia J, Scannevin RH, Zhang X, Huganir RL (2000) Phosphorylation of the AMPA receptor subunit GluR2 differentially regulates its interaction with PDZ domain-containing proteins. J Neurosci 20:7258-7267.

Colledge M, Snyder EM, Crozier RA, Soderling JA, Jin Y, Langeberg LK, Lu H, Bear MF, Scott JD (2003) Ubiquitination regulates PSD-95 degradation and AMPA receptor surface expression. Neuron 40:595-607.

Creager R, Dunwiddie T, Lynch G (1980) Paired-pulse and frequency facilitation in the CA1 region of the in vitro rat hippocampus. J Physiol (Lond) 299:409-424.

D'Ambra TE, Estep KG, Bell MR, Eissenstat MA, Josef KA, Ward SJ, Haycock DA, Baizman ER, Casiano FM, Beglin NC (1992) Conformationally restrained analogues of pravadoline: nanomolar potent, enantioselective, (aminoalkyl)indole agonists of the cannabinoid receptor. J Med Chem 35:124-135.

Debanne D, Guerineau NC, Gahwiler BH, Thompson SM (1996) Pairedpulse facilitation and depression at unitary synapses in rat hippocampus: quantal fluctuation affects subsequent release. J Physiol (Lond) 491:163-176.

Dudek SM, Bear MF (1993) Bidirectional long-term modification of synaptic effectiveness in the adult and immature hippocampus. J Neurosci 13:2910-2918.

Dudek SM, Bowen WD, Bear MF (1989) Postnatal changes in glutamate stimulated phosphoinositide turnover in rat neocortical synaptoneurosomes. Brain Res Dev Brain Res 47:123-128.

Dumas TC, Foster TC (1995) Developmental increase in CA3-CA1 presynaptic function in the hippocampal slice. J Neurophysiol 73:1821-1828.

Esteban JA, Shi SH, Wilson C, Nuriya M, Huganir RL, Malinow R (2003) PKA phosphorylation of AMPA receptor subunits controls synaptic trafficking underlying plasticity. Nat Neurosci 6:136-143.

Feinmark SJ, Begum R, Tsvetkov E, Goussakov I, Funk CD, Siegelbaum SA, Bolshakov VY (2003) 12-Lipoxygenase metabolites of arachidonic acid mediate metabotropic glutamate receptor-dependent long-term depression at hippocampal CA3-CA1 synapses. J Neurosci 23:11427-11435.

Fitzjohn SM, Bortolotto ZA, Palmer MJ, Doherty AJ, Ornstein PL, Schoepp DD, Kingston AE, Lodge D, Collingridge GL (1998) The potent mGlu receptor antagonist LY341495 identifies roles for both cloned and novel mGlu receptors in hippocampal synaptic plasticity. Neuropharmacology 37:1445-1458.

Fitzjohn SM, Palmer MJ, May JE, Neeson A, Morris SA, Collingridge GL (2001) A characterisation of long-term depression induced by metabotropic glutamate receptor activation in the rat hippocampus in vitro. J Physiol (Lond) 537:421-430.

Fuhrmann G, Segev I, Markram H, Tsodyks M (2002) Coding of temporal information by activity-dependent synapses. J Neurophysiol 87:140-148.

Gerdeman GL, Ronesi J, Lovinger DM (2002) Postsynaptic endocannabinoid release is critical to long-term depression in the striatum. Nat Neurosci 5:446-451.

Gifford AN, Tang Y, Gatley SJ, Volkow ND, Lan R, Makriyannis A (1997) Effect of the cannabinoid receptor SPECT agent, AM 281, on hippocampal acetylcholine release from rat brain slices. Neurosci Lett 238:84-86.

Hessler NA, Shirke AM, Malinow R (1993) The probability of transmitter release at a mammalian central synapse. Nature 366:569-572.

Heynen AJ, Yoon BJ, Liu CH, Chung HJ, Huganir RL, Bear MF (2003) Molecular mechanism for loss of visual cortical responsiveness following brief monocular deprivation. Nat Neurosci 6:854-862.

Hsia AY, Malenka RC, Nicoll RA (1998) Development of excitatory circuitry in the hippocampus. J Neurophysiol 79:2013-2024.

Huber KM, Kayser MS, Bear MF (2000) Role for rapid dendritic protein synthesis in hippocampal mGluR-dependent LTD. Science 288:1254-1257.

Huettner JE (2003) Kainate receptors and synaptic transmission. Prog Neurobiol 70:387-407.

Kaneko M, Takahashi T (2004) Presynaptic mechanism underlying cAMPdependent synaptic potentiation. J Neurosci 24:5202-5208.

Kemp N, McQueen J, Faulkes S, Bashir ZI (2000) Different forms of LTD in the CA1 region of the hippocampus: role of age and stimulus protocol. Eur J Neurosci 12:360-366.

Kullmann DM, Erdemli G, Asztely F (1996) LTP of AMPA and NMDA receptor-mediated signals: evidence for presynaptic expression and extrasynaptic glutamate spill-over. Neuron 17:461-474.

Lee HK, Kameyama K, Huganir RL, Bear MF (1998) NMDA induces longterm synaptic depression and dephosphorylation of the GluR1 subunit of AMPA receptors in hippocampus. Neuron 21:1151-1162.

Liao D, Zhang X, O’Brien R, Ehlers MD, Huganir RL (1999) Regulation of morphological postsynaptic silent synapses in developing hippocampal neurons. Nat Neurosci 2:37-43.

Maejima T, Ohno-Shosaku T, Kano M (2001) Endogenous cannabinoid as a retrograde messenger from depolarized postsynaptic neurons to presynaptic terminals. Neurosci Res 40:205-210.

Manabe T, Wyllie DJ, Perkel DJ, Nicoll RA (1993) Modulation of synaptic transmission and long-term potentiation: effects on paired pulse facilitation and EPSC variance in the CA1 region of the hippocampus. J Neurophysiol 70:1451-1459.

Melis M, Pistis M, Perra S, Muntoni AL, Pillolla G, Gessa GL (2004) Endocannabinoids mediate presynaptic inhibition of glutamatergic transmission in rat ventral tegmental area dopamine neurons through activation of $\mathrm{CB}_{1}$ receptors. J Neurosci 24:53-62.

Misner DL, Sullivan JM (1999) Mechanism of cannabinoid effects on longterm potentiation and depression in hippocampal CA1 neurons. J Neurosci 19:6795-6805.

Nicoletti F, Iadarola MJ, Wroblewski JT, Costa E (1986) Excitatory amino acid recognition sites coupled with inositol phospholipid metabolism: developmental changes and interaction with alpha 1-adrenoceptors. Proc Natl Acad Sci USA 83:1931-1935.

Ohno-Shosaku T, Tsubokawa H, Mizushima I, Yoneda N, Zimmer A, Kano M (2002) Presynaptic cannabinoid sensitivity is a major determinant of depolarization-induced retrograde suppression at hippocampal synapses. J Neurosci 22:3864-3872.

Oliet SH, Malenka RC, Nicoll RA (1997) Two distinct forms of long-term depression coexist in CA1 hippocampal pyramidal cells. Neuron 18:969-982.

Overstreet LS, Pasternak JF, Colley PA, Slater NT, Trommer BL (1997) Metabotropic glutamate receptor mediated long-term depression in developing hippocampus. Neuropharmacology 36:831-844.

Palmer E, Nangel-Taylor K, Krause JD, Roxas A, Cotman CW (1990) Changes in excitatory amino acid modulation of phosphoinositide metabolism during development. Brain Res Dev Brain Res 51:132-134.

Petralia RS, Esteban JA, Wang YX, Partridge JG, Zhao HM, Wenthold RJ, Malinow R (1999) Selective acquisition of AMPA receptors over postnatal development suggests a molecular basis for silent synapses. Nat Neurosci 2:31-36.

Pickard L, Noel J, Henley JM, Collingridge GL, Molnar E (2000) Developmental changes in synaptic AMPA and NMDA receptor distribution and AMPA receptor subunit composition in living hippocampal neurons. J Neurosci 20:7922-7931.

Poncer JC, Malinow R (2001) Postsynaptic conversion of silent synapses during LTP affects synaptic gain and transmission dynamics. Nat Neurosci 4:989-996.

Pouzat C, Hestrin S (1997) Developmental regulation of basket/stellate cell $\rightarrow$ Purkinje cell synapses in the cerebellum. J Neurosci 17:9104-9112.

Rammes G, Palmer M, Eder M, Dodt HU, Zieglgansberger W, Collingridge GL (2003) Activation of mGlu receptors induces LTD without affecting postsynaptic sensitivity of CA1 neurons in rat hippocampal slices. J Physiol (Lond) 546:455-460.

Reyes A, Sakmann B (1999) Developmental switch in the short-term modification of unitary EPSPs evoked in layer $2 / 3$ and layer 5 pyramidal neurons of rat neocortex. J Neurosci 19:3827-3835.

Robbe D, Kopf M, Remaury A, Bockaert J, Manzoni OJ (2002) Endogenous cannabinoids mediate long-term synaptic depression in the nucleus accumbens. Proc Natl Acad Sci USA 99:8384-8388.

Rosenmund C, Clements JD, Westbrook GL (1993) Nonuniform probability of glutamate release at a hippocampal synapse. Science 262:754-757.

Rouach N, Nicoll RA (2003) Endocannabinoids contribute to short-term but not long-term mGluR-induced depression in the hippocampus. Eur J Neurosci 18:1017-1020. 
Santschi LA, Stanton PK (2003) A paired-pulse facilitation analysis of longterm synaptic depression at excitatory synapses in rat hippocampal CA1 and CA3 regions. Brain Res 962:78-91.

Sjostrom PJ, Turrigiano GG, Nelson SB (2003) Neocortical LTD via coincident activation of presynaptic NMDA and cannabinoid receptors. Neuron 39:641-654.

Snyder EM, Philpot BD, Huber KM, Dong X, Fallon JR, Bear MF (2001) Internalization of ionotropic glutamate receptors in response to $\mathrm{mGluR}$ activation. Nat Neurosci 4:1079-1085.

Steward O, Falk PM (1985) Polyribosomes under developing spine synapses: growth specializations of dendrites at sites of synaptogenesis. J Neurosci Res 13:75-88.

Steward O, Falk PM (1991) Selective localization of polyribosomes beneath developing synapses: a quantitative analysis of the relationships between polyribosomes and developing synapses in the hippocampus and dentate gyrus. J Comp Neurol 314:545-557.

Varma N, Carlson GC, Ledent C, Alger BE (2001) Metabotropic glutamate receptors drive the endocannabinoid system in hippocampus. J Neurosci 21:RC188(1-5)

Wasling P, Hanse E, Gustafsson B (2004) Developmental changes in release properties of the CA3-CA1 glutamate synapse in rat hippocampus. J Neurophysiol 92:2714-2724.

Watabe AM, Carlisle HJ, O’Dell TJ (2002) Postsynaptic induction and presynaptic expression of group $1 \mathrm{mGluR}$-dependent LTD in the hippocampal CA1 region. J Neurophysiol 87:1395-1403.

Weisskopf MG, Nicoll RA (1995) Presynaptic changes during mossy fibre LTP revealed by NMDA receptor-mediated synaptic responses. Nature 376:256-259.

Xiao MY, Niu YP, Wigstrom H (1997) Comparing long-term depression with pharmacologically induced synaptic attenuations in young rat hippocampi. Synapse 26:329-340.

Xiao MY, Zhou Q, Nicoll RA (2001) Metabotropic glutamate receptor activation causes a rapid redistribution of AMPA receptors. Neuropharmacology 41:664-671.

Xiao MY, Wasling P, Hanse E, Gustafsson B (2004) Creation of AMPAsilent synapses in the neonatal hippocampus. Nat Neurosci 7:236-243.

Yasuda H, Barth AL, Stellwagen D, Malenka RC (2003) A developmental switch in the signaling cascades for LTP induction. Nat Neurosci 6:15-16.

Zakharenko SS, Zablow L, Siegelbaum SA (2002) Altered presynaptic vesicle release and cycling during mGluR-dependent LTD. Neuron 35:10991110. 